\title{
A novel fuzzy based controller to reduce circulating currents in parallel interleaved converter connected to the grid
}

\author{
Sravanthy Gaddameedhi ${ }^{1}$, P. Srinivas ${ }^{2}$ \\ ${ }^{1}$ Department of Electrical and Electronics Engineering, Sree Nidhi Institute of Science and Technology, \\ Hyderabad, Telangana, India \\ ${ }^{2}$ Department of Electrical Engineering, University College of Engineering, Osmania Univesity, \\ Hyderabad, Telangana, India
}

\begin{tabular}{|c|c|}
\hline Article Info & ABSTRACT \\
\hline Article history: & This paper exhibits suppression strategy of low frequency circulating current \\
\hline Received Feb 28, 2020 & $\begin{array}{l}\text { components for parallel inter-leaved converters. Here inverters are parallelized by } \\
\text { magnetically coupled inductors. Traditionally, carrier interleaved technique was }\end{array}$ \\
\hline Revised Aug 12, 2020 & used to get lower distorted output voltage, but it gives a higher circulating \\
\hline Accepted Sep 22, 2020 & $\begin{array}{l}\text { currents to flow through the Two-VSC's. The mutual inductance of the coupled } \\
\text { inductors (CI) is utilized for minimizing circulating currents of high }\end{array}$ \\
\hline Keywords: & $\begin{array}{l}\text { frequency components. Nevertheless, CI can't have capability to riddle the } \\
\text { components generated by low frequency. When these circulating currents }\end{array}$ \\
\hline Circulating current & extremely increases may leads to CI saturation, elevated switching losses and \\
\hline Energy shaping & diminishes the entire performance of system. Here author identified a novel \\
\hline Fuzzy control & $\begin{array}{l}\text { control technique for a grid-connected parallel inter-leaved converter depending } \\
\text { on approach of energy shaping control (ECS). This controller diminishes the }\end{array}$ \\
\hline Parallel interleaved converter & $\begin{array}{l}\text { value of the low frequency components of circulating current (LFCC). The } \\
\text { performance of the proposed circuit is evaluated in simulation mode and } \\
\text { correlated with the conventional proportional integral control (PIC) and the } \\
\text { linear quadratic control (LQC). The Fuzzy controller is also included in this work } \\
\text { to enhance the converter performance effectively and to diminish the circulating } \\
\text { currents along with the healthy harmonic performance analysis. }\end{array}$ \\
\hline
\end{tabular}

This is an open access article under the CC BY-SA license.

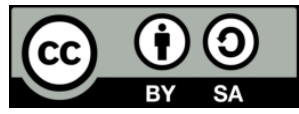

\section{Corresponding Author:}

Sravanthy Gaddameedhi

Department of Electrical and Electronics Engineering

Sree Nidhi Institute of Science and Technology

Yamnampet, Ghatkesar, Hyderabad-501301, Telangana, India

Email: sravanthig@ sreenidhi.edu.in

\section{INTRODUCTION}

In recent times, with the development of power semi-conductor devices, power converters are used in numerous applications like RES and FACTS. For high-power appliances, the converters are connected in parallel are configured as one of the most challenging topology, primarily due to its capability of handling large rating of power, network reliability with efficiency [1]. However, due to the presence of circulating currents, it may lead to distortion in output currents flowing through individual converter, mal-functioning of the power converter devices and deduction in the efficiency [2]. Hence, total harmonic distortion will increase.

In a voltage source inverter, joining each leg in parallel is an approach to amplify the output current and, finally rated power. This type of arrangement is done by coupled or uncoupled inductors, and attaining an equal contribution to the output current from all the legs is a vital issue. Power switching devices subjected to additional losses and stress due to these circulating currents. Consequently, in order minimize 
the effect of these currents; an effective strategy is implemented to obtain balance, when coupled inductors are used is given in [3].

CI provides low conductance with respect to circulating currents. So, without need of additional control equipment it can be able to reduce these currents for balancing. This configuration regulates the harmonic performance analysis of output voltages by adopting exact modulation methods [4]. Often, parallelized inverter carrier pulses are phase shifted by 1800 , which provides several advantages to the system such as escalating no of levels in output voltage, degrading in size of filter and CMV [5].

Furthermore, authors in many papers extended their research on minimizing the circulating currents, which are flowing through the CI. In [6], it is described that common dc bus parallel inverter system for minimization of circulating current using sinusoidal pulse width modulation (SPWM) to overcome the deadtime effects. Design and reasons for having zero sequence circulating currents (ZSCC) in the parallel gridconnected three-phase inverters and reduction of these currents using PI controller are presented in detail [7]. In [8], the author represents a novel zero sequence circulating current reduction method based on the developing selective harmonic elimination pulse-width modulation (SHEPWM) for parallel three-level T-type inverters, which is used to increase the capacity of the distributed generation system.

A modified DPWM technique was presented in [9] to diminish the overall Peak to peak at value of the circulating currents and CMV. To generate reference signals for each particular leg of individual converter, Dongsul Shin et al. developed balancing technique. By utilizing the output currents of individual converter [10], we can determine the reference signals at suitable time intervals, which are equaled to the switching period. Authors have suggested decreasing the magnitude of the circulating currents with deadbeat control technique in [11]. Furthermore, supplementary literature's have focused on their research for the minimization of the ZSCC, which gives a net sum of circulating currents is flowing through all three phases comparatively the individual differential mode currents. The author [12], was proposed that, to restrain these currents a Carrier phase shifted PWM was used in modular bi-level inter-leaved converters. Moreover, two more schemes were introduced in $[13,14]$ for decreasing the ZSCC based on the HEPWM technique. Researchers extend their work to reduce the ZSCC effectively; Karthikeyan et al., introduced a strategy that by adjusting the distribution of the null vectors in the conventional (SVM) scheme through PI controller [15]. All these specified techniques exhibit the magnitude of circulating currents are in allowable permits

In the proposed work, it is recommended to restrict the LFCC by ESC. Here, in order to satisfy energy balance equation, the structure is taken as an energy transformation arrangement. It accomplishes stabilization of passive network by means of HS with a suitable storage function, signifies the essential energy of the closed-loop system. In all power switching converters this type of control technique been used. In [16], to control the operation of a three-phase front end converter this control technique was used. It was used in micro grid applications [17] by controlling back-to-back converters. In [18], for a Tri-level T-type converter with energy storage system, an ESC is developed. To control the circulating currents in parallel interleaved connected power inverters a new dead-time compensation method using carrier based sinusoidal pulse width modulation and modified discontinuous PWM techniques are given in [19, 20]. The inverters are connected in parallel for distributed generation application that operates under different load conditions was investigated in [21] and improved droop control strategy for these converters are developed in [22]. Parallel operation of inverters with active power filters and their control techniques are discussed in detail [23, 24]. The author desires to promote an ESC for a PL-IC. It can be amalgamated for huge power applications such as RES and FACTS. The suggested technique in this paper endeavors a desired controll of LFCC with the appreciable currents injected to the grid.

\section{DESIGN AND MATHEMATICAL MODELING OF THE PARALLEL INTER-LEAVED CONVERTER (PL-IC)}

\subsection{Mathematical model}

This segment gives the representation of the PL-IC, which is tied to the grid by means of an inductive filter shown in Figure 1. The output voltages, $v_{A}, v_{B}$ and $v_{C}$, are the function of switching signals $S_{x i}$ and excitation voltage signal $u_{d c}$. ' $\mathrm{i}$ ' a symbol of the two parallelized VSC $(i\{1,2\})$ and ' $x$ ' indicates the converter phases $(x\{A, B, C\})$. The currents flowing through the grid are indicated as $i_{A}, i_{B}$ and $i_{C}$. In proposed topology, the output voltages w.r.t to the mid-point, ' $O$ ' is written as:

$$
V_{x i}=\frac{v_{d c}}{2}\left(2 S_{x i}-1\right)
$$

The line to ground voltage of converter is represented with the below equations:

$$
v_{A G}=v_{A A 1}+v_{A 1 O}+v_{O G}
$$


$v_{A G}=v_{A A 2}+v_{A 2 O}+v_{O G}$

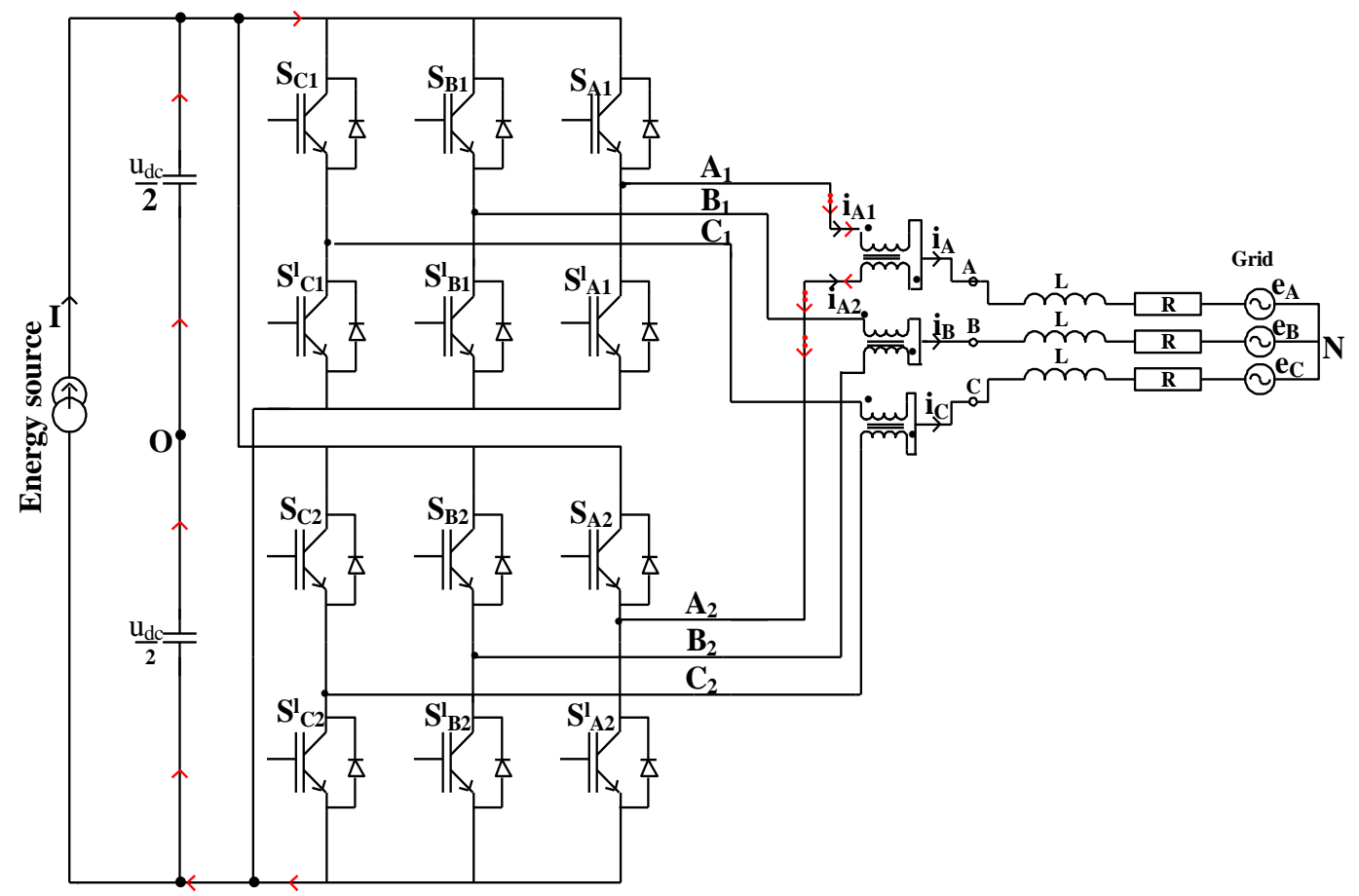

Figure 1. Arrangement of parallel inter-leaved converter

Along with this, the voltage across the couplled inductors can be indicated by:

$$
\begin{aligned}
& v_{A A 1}=-\left(L_{M} \frac{d i_{A 1}}{d t}-L_{M} \frac{d i_{A 2}}{d t}\right)-L_{L} \frac{d i_{A 1}}{d t}-R_{0} i_{A 1} \\
& v_{A A 2}=-\left(L_{M} \frac{d i_{A 2}}{d t}-L_{M} \frac{d i_{A 1}}{d t}\right)-L_{L} \frac{d i_{A 1}}{d t}-R_{0} i_{A 2}
\end{aligned}
$$

In (4), L0 is the mutual inductance and $\mathrm{L}_{\mathrm{L}}$ indicates leekage inductance. So, (2) plus (3) implies:

$$
2 v_{A G}=-L_{L} \frac{d i_{A}}{d t}-R_{0} i_{A}+v_{A_{1} O}+v_{A_{1} O}+2 v_{O G}
$$

Along with; $i_{A_{1}}+i_{A_{2}}=i_{A}$

So VAG can be written as;

$$
v_{A G}=\frac{v_{A_{1} O}+v_{A_{2} O}}{2}-\frac{L_{L}}{2} \frac{d i_{A}}{d t}-\frac{R_{0}}{2} i_{A}+v_{O G}
$$

Likewise, at the two ends of $A_{1}$ and $A_{2}$, the differential voltage is found by the (4):

$$
v_{A_{1} A_{2}}=\left(L_{L}+2 L_{M}\right)\left(\frac{d i_{A 1}}{d t}-\frac{d i_{A 2}}{d t}\right)+R_{0}\left(i_{A_{1}}-i_{A_{2}}\right)
$$

Above expression can be re written as; $i_{C A}=\frac{i_{A_{1}}-i_{A_{2}}}{2}$

Using $i_{C A}$ we will get;

$$
v_{A_{1} O}-v_{A_{2} O}=L_{2} \frac{d i_{C A}}{d t}+2 R_{0} i_{C A}
$$

where $L_{2}=2 L_{L}+4 L_{M}$ 
In addition, with respect to Figure 1, output voltages delivered by the PL-IC are:

$$
\left\{\begin{array}{l}
v_{A G}=R i_{A}+L \frac{d i_{A}}{d t}+e_{A} \\
v_{B G}=R i_{B}+L \frac{d i_{B}}{d t}+e_{B} \\
v_{C G}=R i_{C}+L \frac{d i_{C}}{d t}+e_{C}
\end{array}\right.
$$

Here $\mathrm{R}$ and $\mathrm{L}$ are inductive filter parameters.

From (9) and (5) we will get;

$$
\begin{aligned}
& L \frac{d i_{A}}{d t}=-R i_{A}-e_{A}+\frac{v_{A_{1} O}+v_{A_{2} O}}{2}-\frac{L_{L}}{2} \frac{d i_{A}}{d t}-\frac{R_{0}}{2} i_{A}+v_{O G} \\
& L \frac{d i_{B}}{d t}=-R i_{B}-e_{B}+\frac{v_{B_{1} O}+v_{B_{2}} O}{2}-\frac{L_{L}}{2} \frac{d i_{B}}{d t}-\frac{R_{0}}{2} i_{B}+v_{O G} \\
& L \frac{d i_{C}}{d t}=-R i_{C}-e_{C}+\frac{v_{C_{1} O}+v_{C_{2} O} O}{2}-\frac{L_{L}}{2} \frac{d i_{C}}{d t}-\frac{R_{0}}{2} i_{C}+v_{O G}
\end{aligned}
$$

By substituting (1) in (10), the following relations are obtained.

$$
\begin{aligned}
& L_{1} \frac{d i_{A}}{d t}=-R_{1} i_{A}-e_{A}+\frac{v_{d c}}{4}\left(2 S_{A 1}-1\right)+\frac{v_{d c}}{4}\left(2 S_{A 2}-1\right)+v_{O G} \\
& L_{1} \frac{d i_{B}}{d t}=-R_{1} i_{B}-e_{B}+\frac{v_{d c}}{4}\left(2 S_{B 1}-1\right)+\frac{v_{d c}}{4}\left(2 S_{B 2}-1\right)+v_{O G} \\
& L_{1} \frac{d i_{C}}{d t}=-R_{1} i_{C}-e_{C}+\frac{v_{d c}}{4}\left(2 S_{C 1}-1\right)+\frac{v_{d c}}{4}\left(2 S_{C 2}-1\right)+v_{O G}
\end{aligned}
$$

Here $L_{1}=\left(L+\frac{L_{L}}{2}\right)$ and $R_{1}=\left(R+\frac{R_{0}}{2}\right)$

Similarly by substituting (2) in (8), the dynamics of circulating currents can be obtained as:

$$
\left\{\begin{array}{l}
L_{2} \frac{d i_{C A}}{d t}=-2 R_{0} i_{C A}-e_{A}+\frac{v_{d c}}{2}\left(2 S_{A 1}-1\right)-\frac{v_{d c}}{2}\left(2 S_{A 2}-1\right) \\
L_{2} \frac{d i_{C B}}{d t}=-2 R_{0} i_{C B}-e_{B}+\frac{v_{d c}}{2}\left(2 S_{B 1}-1\right)-\frac{v_{d c}}{2}\left(2 S_{B 2}-1\right) \\
L_{2} \frac{d i_{C C}}{d t}=-2 R_{0} i_{C C}-e_{C}+\frac{v_{d c}}{2}\left(2 S_{C 1}-1\right)-\frac{v_{d c}}{2}\left(2 S_{C 2}-1\right)
\end{array}\right.
$$

The above expression can be reduced to more simple by using Parks transformation, which renovates the (11) and (12) in to the revolving frame $d q$, coordinated with respect to angle of grid $\theta g r$. Hence, the dynamic of the PL-IC is given by:

$$
\begin{aligned}
& \left\{\begin{array}{l}
L_{1} \frac{d i_{d}}{d t}=-R_{1} i_{d}+\omega L_{1} i_{q}-e_{g r d}+\frac{u_{d c}}{4} S_{d 1}+\frac{u_{d c}}{4} S_{d 2} \\
L_{1} \frac{d i_{d}}{d t}=-R_{1} i_{q}+\omega L_{1} i_{d}-e_{g r q}+\frac{u_{d c}}{4} S_{q 1}+\frac{u_{d c}}{4} S_{q 2}
\end{array}\right. \\
& \left\{\begin{array}{l}
L_{2} \frac{d i_{c_{-} d}}{d t}=-2 R_{0} i_{c_{-} d}+\omega L_{2} i_{c_{-} q}+\frac{v_{d c}}{2} S_{d 1}-\frac{v_{d c}}{2} S_{d 2} \\
L_{2} \frac{d i_{c_{-} q}}{d t}=-2 R_{0} i_{c_{-} q}-\omega L_{2} i_{c_{-} d}+\frac{v_{d c}}{2} S_{q 1}-\frac{v_{d c}}{2} S_{q 2}
\end{array}\right.
\end{aligned}
$$

$S_{d 1}, S_{d 2}, S_{q 1}$ and $S_{q 2}$ are Switching Functions of direct, quadrature axis for the two paralleled converters.

\subsection{Port carrey Hamilton (PCH) model of the PL-IC}

The converter is considered as an inactive system as it can merely exchange's energy, but it doesn't has the capability of delivering on its own. Consequently, it can be designed as PCH system that satisfies the necessities of ECS. The configuration is:

$$
\begin{aligned}
& \dot{x}=[J(x)-R(x)] \frac{\partial E(x)}{\partial x}+\mathrm{p}(\mathrm{x}) \mathrm{u} \\
& \mathrm{y}=p^{T}(\mathrm{x}) \frac{\partial E(x)}{\partial x}
\end{aligned}
$$

In (14), $J(x)$ is the bridge matrix taken as an anti-symmetric $\left(J(x)=J(x)^{T}\right) . R(x)$, symmetric matrix. $p(x)$, external port matrix an $E(x)$, energy function of the system. In (14), $u$ and $y$ are excitation and output parameters of the system. The relation (13) is represented by: 


$$
\begin{aligned}
& \left(\begin{array}{c}
L_{1} i_{d} \\
L_{1} i_{q} \\
L_{2} i_{c_{-} d} \\
L_{2} i_{c_{-} q}
\end{array}\right)=\left(\begin{array}{cccc}
0 & \omega L_{1} & 0 & 0 \\
-\omega L_{1} & 0 & 0 & 0 \\
0 & 0 & 0 & \omega L_{2} \\
0 & 0 & -\omega L 2 & 0
\end{array}\right)-\left(\begin{array}{cccc}
R_{1} & 0 & 0 & 0 \\
0 & R_{1} & 0 & 0 \\
0 & 0 & 2 R_{0} & 0 \\
0 & 0 & 0 & 2 R_{0}
\end{array}\right)\left(\begin{array}{c}
i_{d} \\
i_{q} \\
i_{c_{-} d} \\
i_{c_{-} q}
\end{array}\right) \\
& +\frac{V_{d c}}{4}\left(\begin{array}{cccc}
1 & 0 & 1 & 0 \\
0 & 1 & 0 & 1 \\
2 & 0 & -2 & 0 \\
0 & 2 & 0 & -2
\end{array}\right)\left(\begin{array}{c}
S_{d 1} \\
S_{q 1} \\
S_{d 2} \\
S_{q 2}
\end{array}\right)-\left(\begin{array}{l}
1 \\
0 \\
0 \\
0
\end{array}\right) e_{\text {gridd- }}\left(\begin{array}{cc}
0 \\
1 \\
0 \\
0
\end{array}\right) e_{g r i d q} \\
& \text { with } \mathrm{j}(\mathrm{x})=\left(\begin{array}{cccc}
0 & \omega L_{1} & 0 & 0 \\
-\omega L_{1} & 0 & 0 & 0 \\
0 & 0 & 0 & \omega L_{2} \\
0 & 0 & -\omega L 2 & 0
\end{array}\right) \text { and } \mathrm{R}(\mathrm{x})=\left(\begin{array}{cccc}
R_{1} & 0 & 0 & 0 \\
0 & R_{1} & 0 & 0 \\
0 & 0 & 2 R_{0} & 0 \\
0 & 0 & 0 & 2 R_{0}
\end{array}\right)
\end{aligned}
$$

From the above discussion, clearly (14) it is considered as PCH. The HF,

$$
\begin{aligned}
& \mathrm{h}(\bar{x})=\frac{1}{2} L_{1} i_{d}^{2}+\frac{1}{2} L_{1} i_{q}^{2}+\frac{1}{2} L_{2} i_{c_{-} d}^{2}+\frac{1}{2} L_{2} i_{c_{-}}^{2} q \\
& \text { And } \mathrm{x}=\left[\begin{array}{llll}
L_{1} i^{d} & L_{1} i^{q} & L_{2} i^{c_{-} d} & L_{2} i^{c_{-} q}
\end{array}\right]
\end{aligned}
$$

The external port connection matrices are specified by:

$$
p_{1}=\frac{V_{d c}}{4}\left(\begin{array}{cccc}
1 & 0 & 1 & 0 \\
0 & 1 & 0 & 1 \\
2 & 0 & -2 & 0 \\
0 & 2 & 0 & -2
\end{array}\right) ; p_{2}=\left(\begin{array}{cccc}
1 & 0 & 0 & 0
\end{array}\right)^{T} ; p_{3}=\left(\begin{array}{llll}
0 & 1 & 0 & 0
\end{array}\right)^{T}
$$

$h(\bar{x})$ can be given as:

$$
\mathrm{h}(\bar{x})=\frac{1}{2 L_{1}}\left(L^{1} i^{d}\right)^{2}+\frac{1}{2 L_{1}}\left(L^{1 \prime} i^{q}\right)^{2}+\frac{1}{2 L_{2}}\left(L^{2} i^{c_{-} d}\right)^{2}+\frac{1}{2 L_{2}}\left(L^{2} i^{c_{-} q}\right)^{2}
$$

If the state variables may be referred as $x_{1}, x_{2}, x_{3}$ and $x_{4} ;(18)$ becomes:

$$
\mathrm{h}(\bar{x})=\frac{1}{2 L_{1}}\left(x_{1}\right)^{2}+\frac{1}{2 L_{1}}\left(x_{2}\right)^{2}+\frac{1}{2 L_{1}}\left(x_{3}\right)^{2}+\frac{1}{2 L_{1}}\left(x_{4}\right)^{2}
$$

Therefore, the HF Gradient is defined as:

$$
\frac{\partial h(\bar{x})}{\partial x}=\left[\frac{\partial h}{\partial x_{1}} \frac{\partial h}{\partial x_{2}} \frac{\partial h}{\partial x_{3}} \frac{\partial h}{\partial x_{4}}\right]^{T}=\left[\begin{array}{llll}
i_{d} & i_{q} & i_{c_{-} d} & i_{q_{-} d}
\end{array}\right]^{T}
$$

\section{CONTROL SCHEMES FOR GRID CONNECTED CONVERTER (GCC)}

\subsection{PIC based GCC}

The control process of the PI-LC with PIC is shown in Figure 2. In order to measure current and voltage at the PCC to the grid, voltage and current sensors was used. By means of PLL, the grid phase angle $\theta_{\text {grid }}$ is obtained. The target is attained by setting the $e^{*}$ gridd. to zero. PI controler is utilized to adjust the grid angle with respect to the error between $e^{*}{ }_{\text {gridd }}$ and $e_{\text {gridd }}$. So, the grid voltage vector is associated with the $q$ axis of the revolving frame. This conventional control is studied earlier in enormous literature's [5]. The expressions of $\mathrm{P}$ and $\mathrm{Q}$ supplied to grid are given as: 


$$
\left\{\begin{array}{l}
\mathrm{P}^{\text {grid }}=\mathrm{e}_{\text {gridd }} \mathrm{i}^{\mathrm{d}}+\mathrm{e}_{\text {gridq }} \mathrm{i}^{\mathrm{q}} \\
\mathrm{Q}^{\text {grid }}=\mathrm{e}_{\text {gridd }} \mathrm{i}^{\mathrm{d}}-\mathrm{e}_{\text {gridq }} \mathrm{i}^{\mathrm{q}}
\end{array}\right.
$$

Based on (21), current set points, $\mathrm{i}_{\mathrm{d}}^{*}$ and $\mathrm{i}_{\mathrm{q}}^{*}$ are achieved by the grid voltages, $\mathrm{P}_{\text {grid }}^{*}$ and $\mathrm{Q}_{\text {grid }}^{*}$

$$
\begin{aligned}
& i_{d}^{*}=\frac{\mathrm{P}_{\text {grid }}^{*} \mathrm{e}_{\text {gridd }}+Q_{\text {grid }}^{*} \mathrm{e}_{\text {gridq }}}{\mathrm{e}_{\text {gridd }}^{2}+\mathrm{e}_{\text {gridq }}^{2}} \\
& i_{q}^{*}=\frac{P_{\text {grid }}^{*} e_{\text {gridd }}-Q_{\text {grid }}^{*} e_{\text {gridq }}}{e_{\text {gridd }}^{2}+e_{\text {gridq }}^{2}}
\end{aligned}
$$

With the help of differential equations, the control pattern is built from the elements in the grid and represented in " $d q$ " by:

$$
L_{1} \bar{l}_{d, q}+L_{1} \bar{l}_{d, q}=\bar{v}_{i d, q}-j L_{1} \omega_{\text {grid }} \bar{l}_{d, q}-\bar{e}_{\text {gridd }, q}
$$

In the above expressions, $\bar{v}_{i d, q}$ indicates the voltage vector generated by the PI-LC.

\subsection{LQC based GCC}

Inverter connected to the grid with LQC is shown in Figure 3. The improvement in the controller is achieved by the state space representation which is given by (16). Hence,

$$
\left\{\begin{array}{c}
\dot{x}_{l q}=\mathrm{A} x_{l q}+\mathrm{B} u_{s} \\
y_{l q}=\mathrm{C} x_{l q}
\end{array}\right.
$$

where $\mathrm{Y}$ yields output vector i.e, $\mathrm{y}=\left\lfloor i_{d} i_{q}\right\rfloor^{T}$

$u_{s}$ is input vector $\left[v_{i d}-e_{\text {gridd }} v_{i q}-e_{\text {gridq }}\right\rfloor^{T}$

$$
\mathrm{A}=\left(\begin{array}{cc}
\frac{-R_{1}}{L_{1}} & \omega_{\text {grid }} \\
\omega_{\text {grid }} & \frac{-R_{1}}{L_{1}}
\end{array}\right) ; \mathrm{B}=\left(\begin{array}{cc}
\frac{1}{L_{1}} & 0 \\
0 & \frac{1}{L_{1}}
\end{array}\right) ; \mathrm{C}=\left(\begin{array}{cc}
1 & 0 \\
0 & 1
\end{array}\right)
$$

Stabilizing feedback matrix $K_{d}$ is efficiently calculated by LQC technique. It satisfies the overall performances of energy control and transient response. The modelling of this controller is given in detail [25].

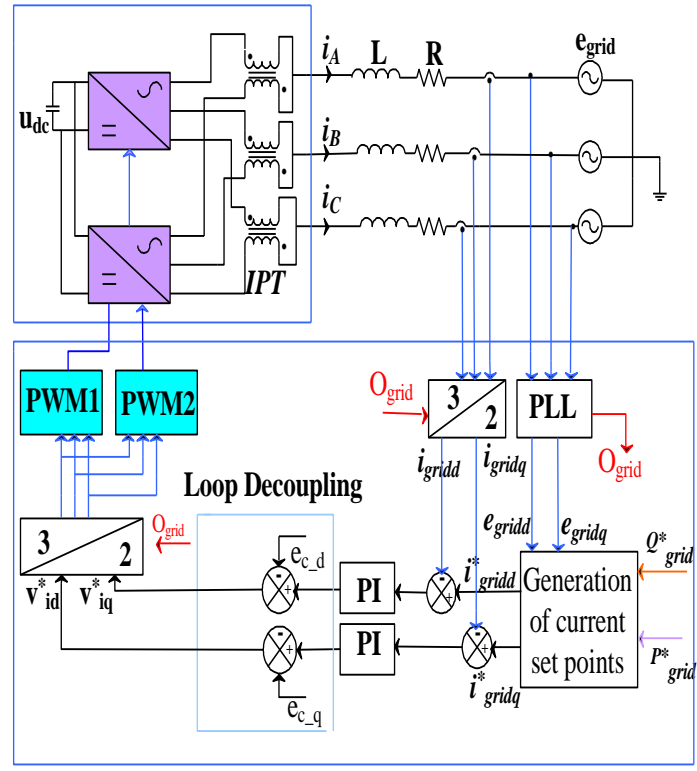

Figure 2. Converter connected to the grid with PIC
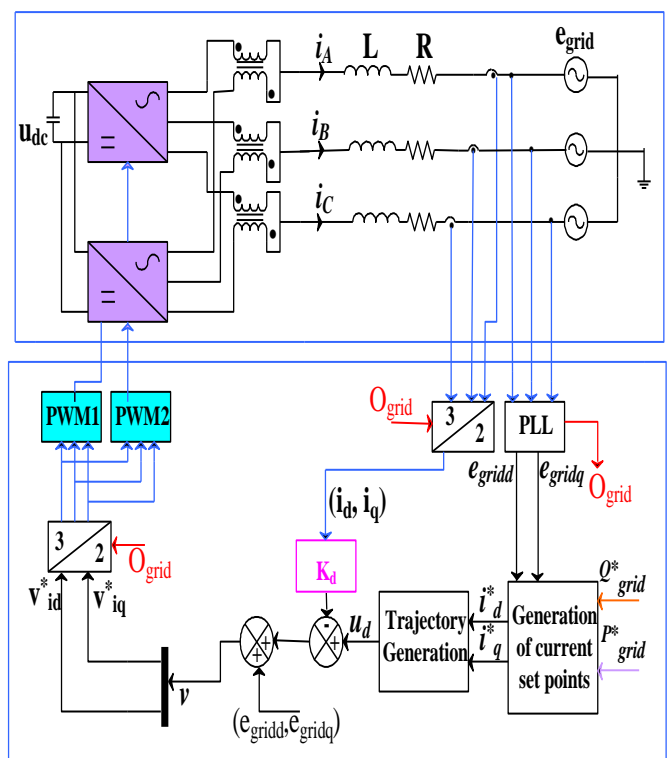

Figure 3. Converter connected to the grid with LQC 


\subsection{ESC based GCC}

GCC satisfies the PCH notation given in (17). In PCH, bridge and the damping matrices can handle internal energy exchange efficiently [26]. Finally, the preferred configuration is shown below:

$$
\begin{aligned}
& \dot{x}=\left[J_{p}(x)-R_{p}(x)\right] \frac{\partial H_{p}(x)}{\partial x} \\
& \text { with }\left\{\begin{array}{c}
J_{p}(x)=\mathrm{J}(\mathrm{x})+J_{\alpha}(x) \\
R_{p}(x)=\mathrm{R}(\mathrm{x})+R_{\alpha}(x)
\end{array}\right.
\end{aligned}
$$

where, $J_{p}(x)$ denotes the preferable bridge matrix, $R_{p}(x)$ is preferable dissipation matrix and $H_{p}(x)$ is expected energy function respectively.

$$
J_{\alpha}(x)=\left(\begin{array}{cccc}
0 & \omega L_{1} & 0 & 0 \\
-\omega L_{1} & 0 & 0 & 0 \\
0 & 0 & 0 & \omega L_{2} \\
0 & 0 & -\omega L 2 & 0
\end{array}\right) ; R_{\alpha}(x)=\left(\begin{array}{cccc}
r_{1} & 0 & 0 & 0 \\
0 & r_{1} & 0 & 0 \\
0 & 0 & r_{2} & 0 \\
0 & 0 & 0 & r_{2}
\end{array}\right)
$$

$r_{1}$ and $r_{2}$ are a positive numerical. ESC permit $u=\gamma(x)$ such that the dynamic behavior of the closed loop system are illustrated in (24). Here, the motive is to track the current set points efficiently by proper designing of controler. Hence, the required energy function of PL-IC is given by:

$$
H_{d}(x)=\frac{1}{2} L_{1}\left(i_{d}-i_{d}^{*}\right)^{2}+\frac{1}{2} L_{1}\left(i_{q}-i_{q}^{*}\right)^{2}+\frac{1}{2} L_{2}\left(i_{c_{d}}-i_{c_{d}}^{*}\right)^{2}+\frac{1}{2} L_{2}\left(i_{c_{q}}-i_{c_{q}}^{*}\right)^{2}
$$

Here $i_{c_{-} d}^{*}$ and $i_{c_{-} q}^{*}$ shows the circulating currents set points. The gradient of required Hamilton function (HF) and the distinct state vector is represented by:

$$
\begin{aligned}
& \nabla H_{d}(x)=\left[\begin{array}{lll}
\frac{\partial H_{d}}{\partial x_{1}} \frac{\partial H_{d}}{\partial x_{2}} \frac{\partial H_{d}}{\partial x_{3}} \frac{\partial H_{d}}{\partial x_{4}}
\end{array}\right]^{T}=\left(\begin{array}{c}
i_{d}-i_{d}^{*} \\
i_{q}-i_{q}^{*} \\
i_{c_{-} d}-i_{c_{c_{-}} d}^{*} \\
i_{c_{-} q}-i_{c_{-} q}^{*}
\end{array}\right) \\
& \mathrm{X}=\left[\begin{array}{llll}
L_{1}\left(i_{d}-i_{d}^{*}\right) & L_{1}\left(i_{q}-i_{q}^{*}\right) & L_{2}\left(i_{c_{-} d}-i_{c_{-} d}^{*}\right) & L_{2}\left(i_{c_{-} q}-i_{c_{-} q}^{*}\right)
\end{array}\right]^{T}
\end{aligned}
$$

ESC attains the stabilization guided by the expected $\operatorname{Hd}(\mathrm{x})$. The control input $\mathrm{u}$ of network is obtained as:

$$
[\mathrm{J}(x)-\mathrm{R}(x)] \frac{\partial H(x)}{\partial x}+g(x) u=\left[J_{d}(x)-R_{d}(x)\right] \frac{\partial H_{d}(x)}{\partial x}
$$

If the system functions nearest to the expected point, then the $H_{d}(x)$ tries to maintain at the lowest value. So, (15) should satisfy:

$$
\begin{aligned}
& \left(\begin{array}{cccc}
0 & \omega L_{1} & 0 & 0 \\
-\omega L_{1} & 0 & 0 & 0 \\
0 & 0 & 0 & \omega L_{2} \\
0 & 0 & -\omega L 2 & 0
\end{array}\right)-\left(\begin{array}{cccc}
R_{1} & 0 & 0 & 0 \\
0 & R_{1} & 0 & 0 \\
0 & 0 & 2 R_{0} & 0 \\
0 & 0 & 0 & 2 R_{0}
\end{array}\right)\left(\begin{array}{c}
i_{d} \\
i_{q} \\
i_{c_{-} d} \\
i_{c_{-} q}
\end{array}\right) \\
& +\left(\begin{array}{c}
S_{d 1} \\
S_{q 1} \\
2 S_{d 1} \\
2 S_{q 1}
\end{array}\right) \frac{u_{d c}}{4}-\left(\begin{array}{c}
S_{d 2} \\
S_{q 2} \\
-2 S_{d 2} \\
-2 S_{q 2}
\end{array}\right) \frac{u_{d c}}{4}-\left(\begin{array}{c}
e_{\text {gridd }} \\
e_{\text {gridq }} \\
0 \\
0
\end{array}\right)=0
\end{aligned}
$$

At steady-state point, output currents are identically distributed among converters and hence zero circulating currents flowing through a system $\left(i_{c_{-} d}=i_{c_{-} q}=0\right)$. Steady- state values are determined by $(31)$ : 


$$
\left\{\begin{array}{l}
s_{d 1}^{*}=s_{d 2}^{*}=s_{d 0}^{*}=\frac{-\omega L_{1} i_{q}^{*}+R_{1} i_{d}^{*}+e_{\text {gridd }}}{\frac{u_{d c}}{2}} \\
s_{q 1}^{*}=s_{q 2}^{*}=s_{q 0}^{*}=\frac{-\omega L_{1} i_{d}^{*}+R_{1} i_{q}^{*}+e_{\text {gridq }}}{\frac{u_{d c}}{2}}
\end{array}\right.
$$

The control action $u=\left[\begin{array}{llll}s_{d 1}^{*} & s_{d 2}^{*} & s_{q 1}^{*} & s_{q 2}^{*}\end{array}\right]^{T}$ is opted by the matching (30). Assuming $i_{c_{-}}^{*}=i_{c_{-} q}^{*}=0$, the solution of (26) gives:

$$
\begin{aligned}
& \frac{s_{d 1}^{*}+s_{d 2}^{*}}{2}=s_{d 0}^{*}+\frac{\omega L_{1}\left(i_{q}-i_{q}^{*}\right)+r_{1}\left(\left(i_{d}-i_{d}^{*}\right)\right.}{\frac{u_{d c}}{2}} \\
& \frac{s_{q 1}^{*}+s_{q 2}^{*}}{2}=s_{q 0}^{*}-\frac{\omega L_{1}\left(i_{d}-i_{d}^{*}\right)+r_{1}\left(\left(i_{q}-i_{q}^{*}\right)\right.}{\frac{u_{d c}}{2}} \\
& s_{d 1}^{*}-s_{d 2}^{*}=\frac{\omega L_{2} i_{c_{-}-q}+r_{2} i_{c-d}}{\frac{u_{d c}}{2}} \\
& s_{q 1}^{*}-s_{q 2}^{*}=\frac{-\omega L_{2} i_{c-d}-r_{2} i_{c-q}}{\frac{u_{d c}}{2}}
\end{aligned}
$$

The response obtained from (33)-(36) are considered as $b_{1}, b_{2}, b_{3}$ and $b_{4}$ respectively. Further, these equations are expressed as:

$$
\begin{aligned}
& Z_{e}=\left(\begin{array}{c}
s_{d 1}^{*} \\
s_{d 2}^{*}
\end{array}\right)=B_{1} \\
& Z_{e}=\left(\begin{array}{c}
s_{q 1}^{*} \\
s_{q 2}^{*}
\end{array}\right)=B_{2} \\
& \mathrm{i}^{\text {th }}, Z_{e}=\left(\begin{array}{cc}
\frac{1}{2} & \frac{1}{2} \\
1 & -1
\end{array}\right), B_{1}=\left(\begin{array}{c}
b_{1} \\
b_{3}
\end{array}\right), B_{1}=\left(\begin{array}{c}
b_{2} \\
b_{4}
\end{array}\right)
\end{aligned}
$$

Solutions from (37) and (38) give the desired excitation for the two paralleled converters. The switching function which is taken as reference is calculated smoothly with the help of the inverse of matrix A. Figure 4 shows the block diagram of a control structure for determining the reference switching function with ESC. The DC bus voltage controlling is similar to the PIC.

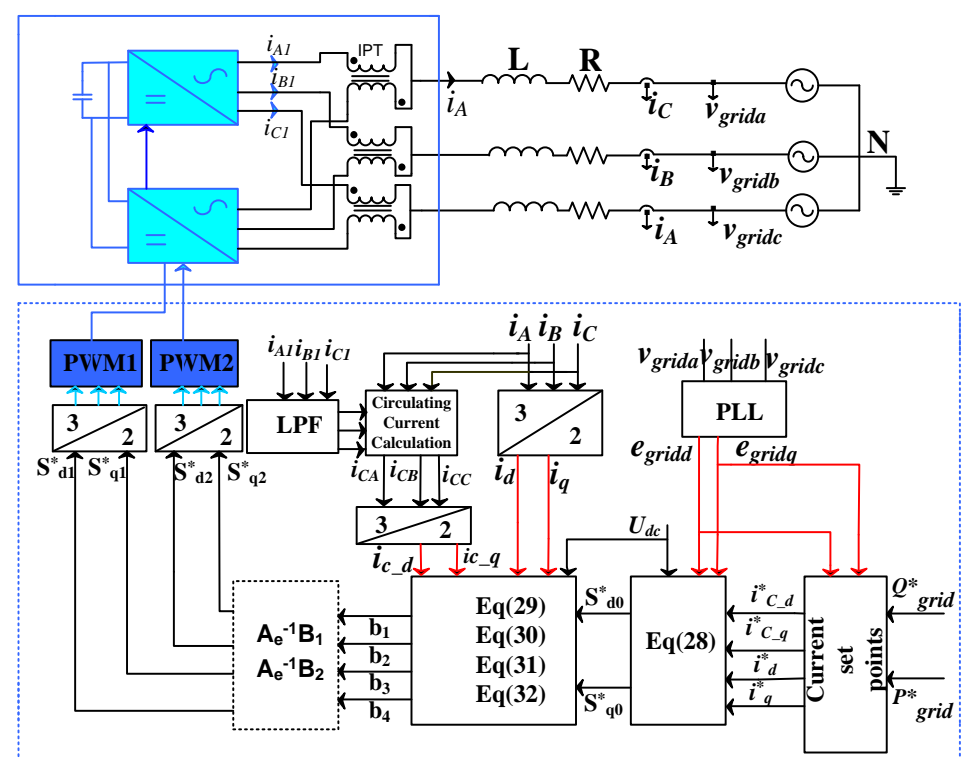

Figure 4. Converter connected to the grid with ESC 


$$
\begin{aligned}
& \left(\begin{array}{l}
s_{d 1}^{*} \\
s_{d 2}^{*}
\end{array}\right)=Z_{e}^{-1}\left(\begin{array}{l}
b_{1} \\
b_{3}
\end{array}\right) \\
& \left(\begin{array}{l}
s_{q 1}^{*} \\
s_{q 2}^{*}
\end{array}\right)=Z_{e}^{-1}\left(\begin{array}{l}
b_{2} \\
b_{4}
\end{array}\right)
\end{aligned}
$$

where $Z_{e}^{-1}=\left(\begin{array}{cc}1 & \frac{1}{2} \\ 1 & -\frac{1}{2}\end{array}\right)$

\section{SUMMARY OF RESULTS}

Here, the performance of the converter with different controllers is given. The converter results with PIC, LQC and ESC are obtained and with ESC the performance of the converter is achieved better as compared to PIC and LQC in terms of reducing the circulating currents.

\subsection{Converter performance with PIC}

Figure 5 gives the function of the system with PIC. Figure 5(a) portrays the current delivered to the grid and Figure 5(b) describes the currents flowing through the converter delivered by phase's $\mathrm{C} 1$ and $\mathrm{C} 2$. From Figure 5(b), magnitude of the current in converter 1 is considerably larger than the magnitude of the current in converter 2 . Hence, the sharing of the grid currents in the two converters are unequal leads to LFCC's. The dc offset component of circulating current can attain 0.5A (iCC) as exhibited in Figure 5(c), which is nearly 30\% of the magnitude of the grid current. Consequently, abandoned circulating currents are larger in magnitude, which may lead to saturation of coupling inductors. Additionally, it raises the power converters switching losses. P and Q delivered to the grid are demonstrated in Figure 5(d).

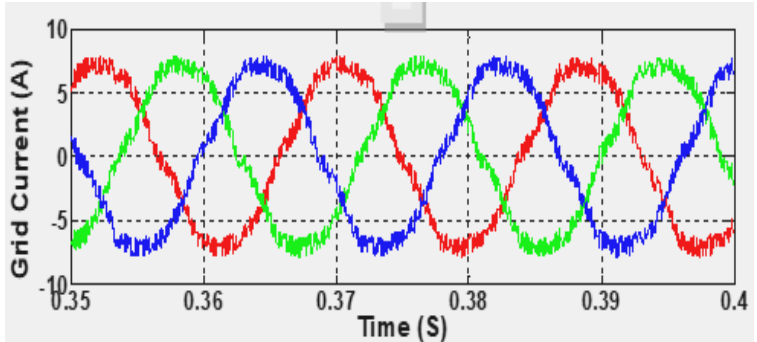

(a)

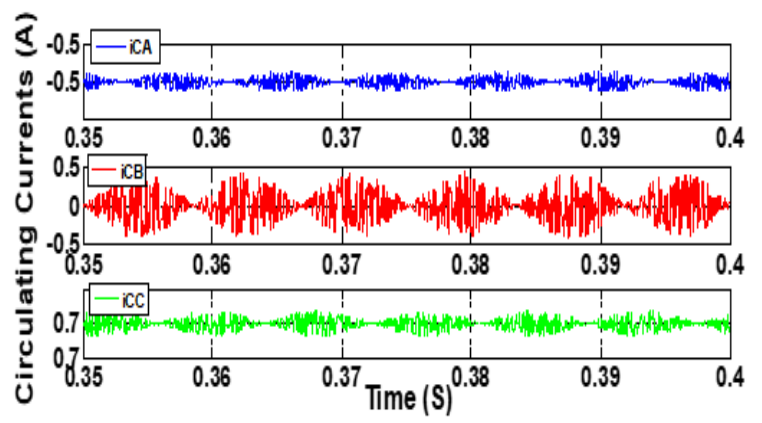

(c)

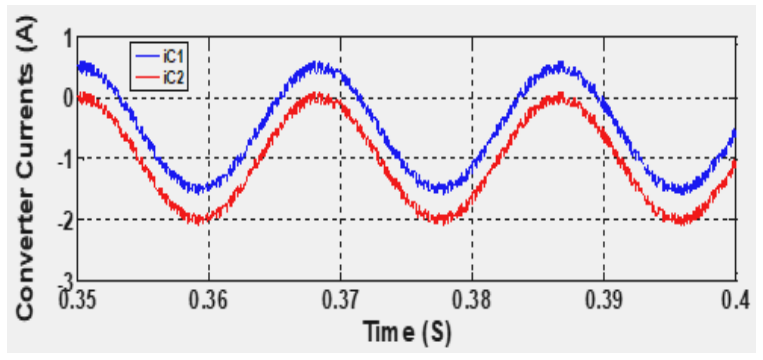

(b)

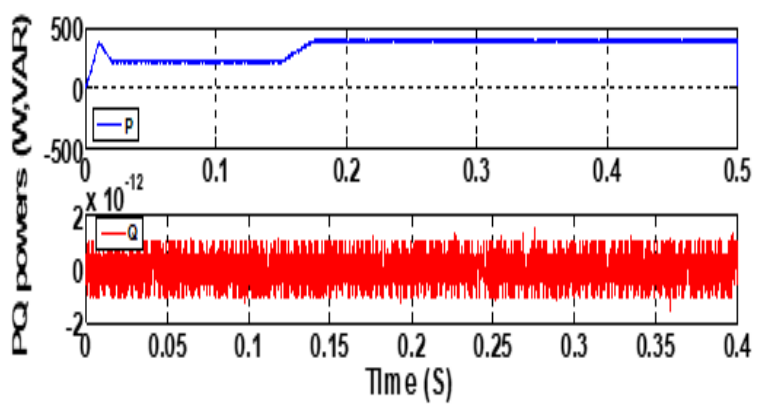

(d)

Figure 5. Performance of converter with PIC, (a) grid current, (b) converter currents, (c) difference mode currents, (d) PQ powers

\subsection{Converter performance with $L Q C$}

Figure 6 gives the function of the GCC with the LQC. The results are obtained with LQC is very nearer to the results with PIC. Even so, still some considerable amount of circulating currents are present in the two converters as shown in Figure 6(a) and grid powers shown in Figure 6(b). 


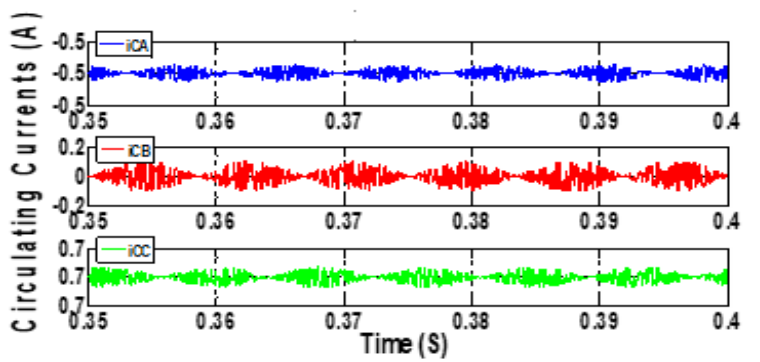

(a)

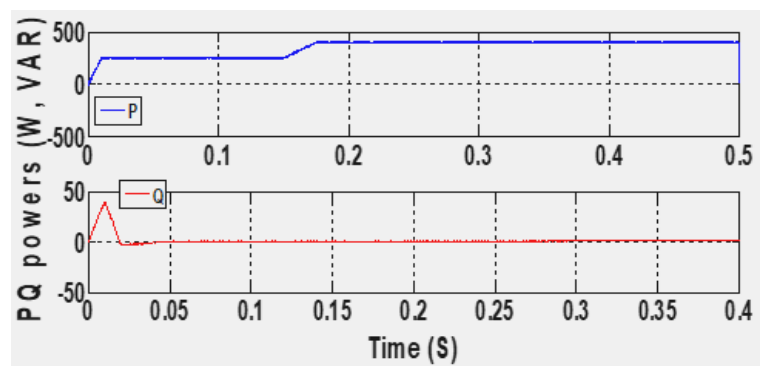

(b)

Figure 6. Performance of converter with LQC, (a) difference mode currents, (b) grid powers

\subsection{Converter performance with ESC}

Figure 7 gives the behaviour of the grid with ESC. The currents which are supplied to the grid are illustrated in Figures 7(a) and (b) describes the currents flowing through the converters delivered by phases $\mathrm{C} 1$ and $\mathrm{C} 2$. In this case it is noticed that, currents are distributed identically between the converters. Additionally, the dc component of circulating currents for three phases is diminished to zero and only circulating currents which are having high frequency travels among two Converters as shown in Figure 7(c) and Figure (d) shows the converter powers. The DC bus voltage remains stable as represented in Figure 7(f).

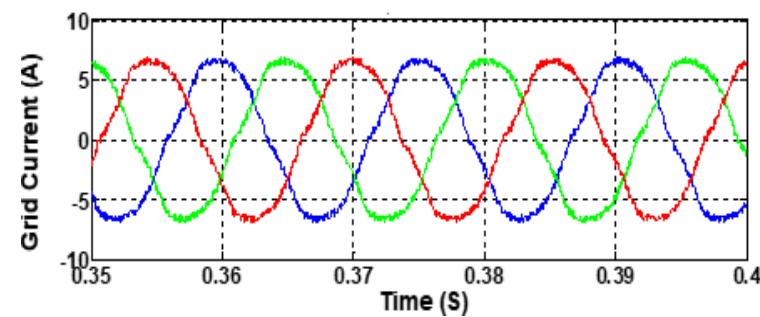

(a)

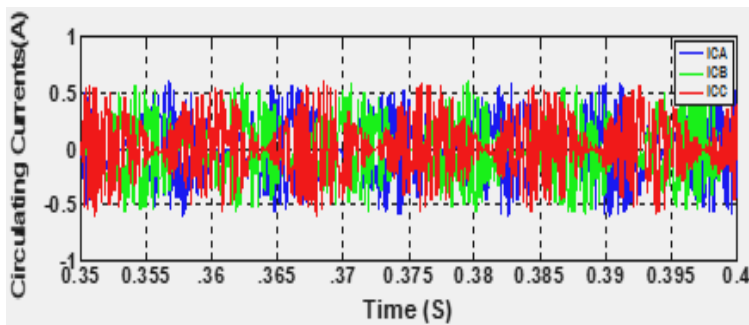

(c)

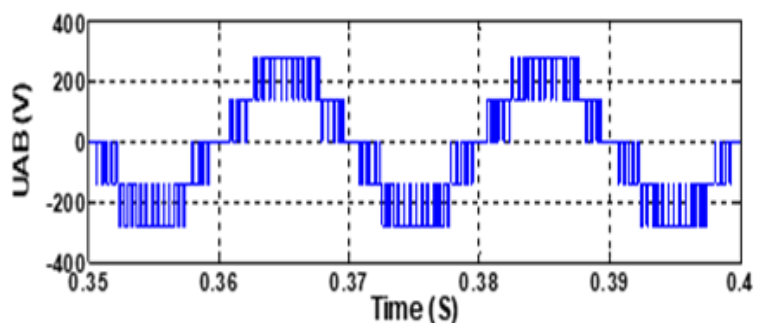

(e)

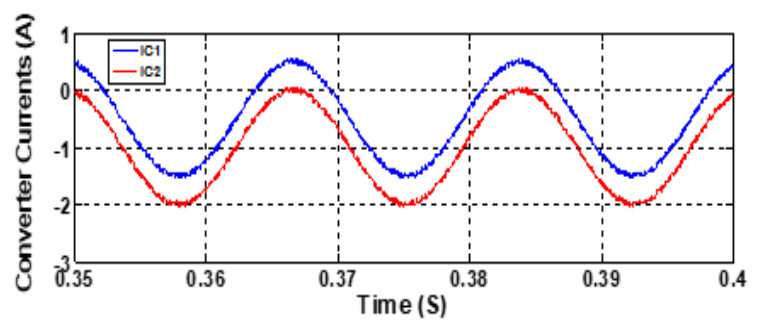

(b)

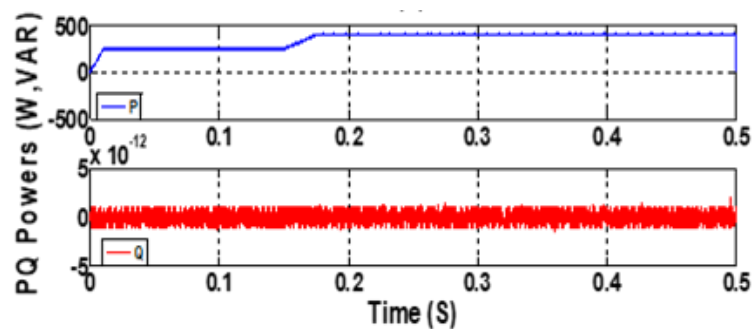

(d)

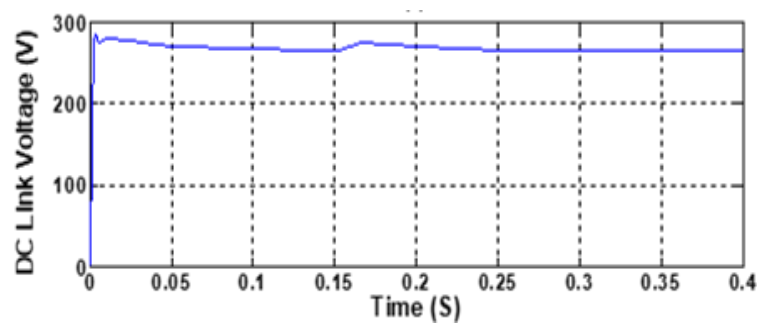

(f)

Figure 7. Performance of converter with ESC, (a) grid current, (b) converter currents, (c) difference mode currents, (d) grid powers, (e) VAB, (f) dc bus voltage

\subsection{Converter behavior with fuzzy control}

Figure 8 exhibits grid behavior with fuzzy control. The currents, which are supplied to grid are illustrated on Figure 8(a). Whereas, Figure 8(b) describe the currents flowing through the converters 
delivered by phases $\mathrm{C} 1$ and $\mathrm{C} 2$. In this case it has been noticed that, current flowing through the individual converters are distributed identically.

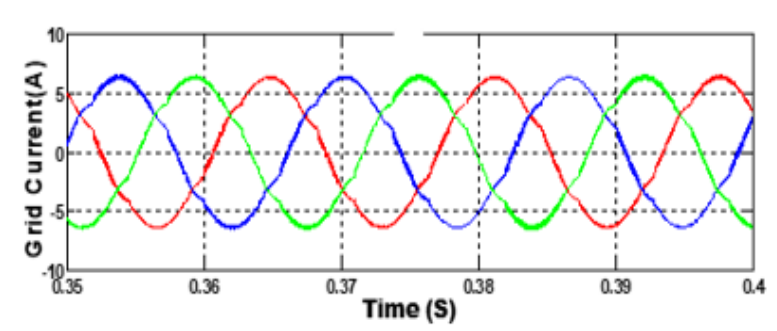

(a)

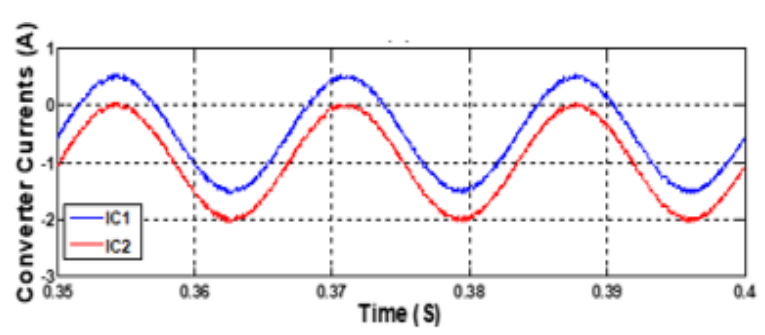

(b)

Figure 8. Performance of converter with fuzzy control, (a) grid current, (b) converter currents

Figures 9 (a, b, c, d) shows that harmonic spectrum analysis of grid and converter currents with ESC and fuzzy control techniques. Clearly it can be observed that with Fuzzy the harmonic content in the grid current and converter currents are reduced effectively. Along with the harmonic analysis, it is proved that the LFCC components also minimized with fuzzy control efficiently.

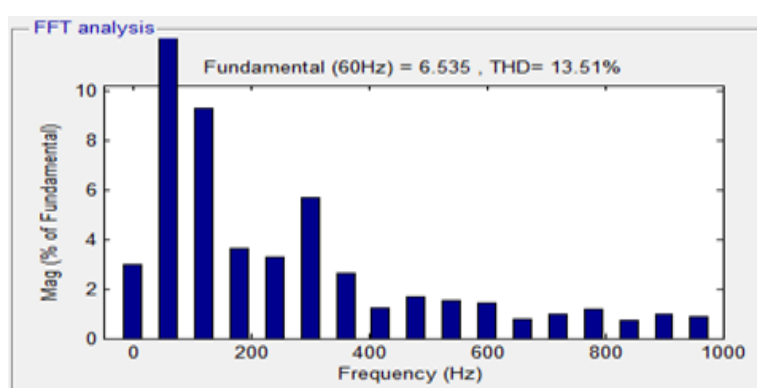

(a)

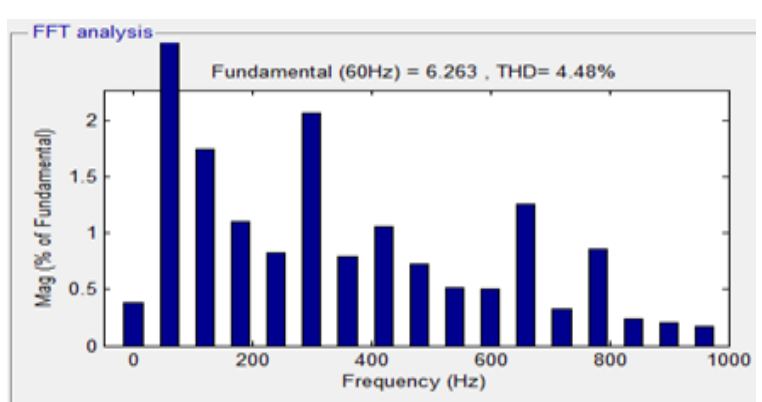

(c)

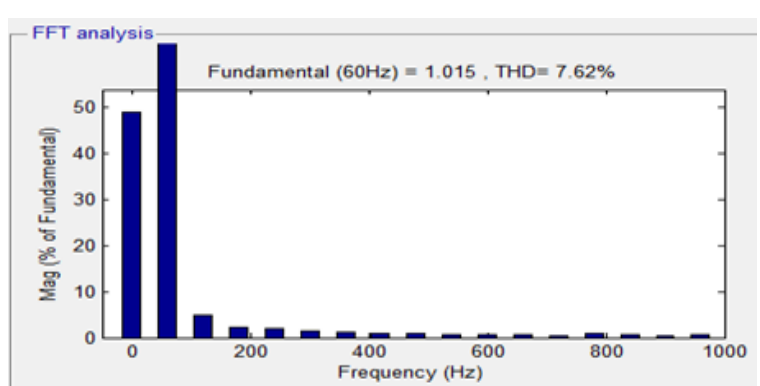

(b)

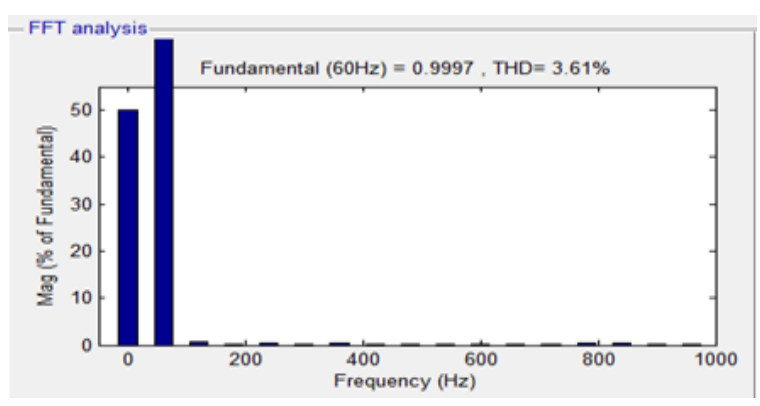

(d)

Figure 9. Harmonic spectrum analysis, (a) grid currents with ES, (b) grid currents with fuzzy, (c) converter currents with ESC, (d) converter currents with fuzzy

\section{CONCLUSION}

Converter legs connected in inter-leaved configuration improves the maximum power through each converter but generates circulating currents within the converter legs that should be minimized for efficient functioning of the system. This becomes more challenging at low switching frequencies as unequal voltages between the inter-leaved converters are generally applied for longer time intervals. The reduction of these circulating currents in each phase of two inter-leaved converter leg with PIC, LQC, ESC and fuzzy controllers is studied in this paper. The recommended controller is further implemented by an evaluation and optimal selection of SPWM patterns, which reduce the peak of the circulating currents. Simulation results demonstrate and confirm the performance of the recommended controller. 


\section{REFERENCES}

[1] R. Maheshwari, G. Gohil, "Analysis and Modeling of circulating current in two parallel connected Inverters," IET power electronics, vol. 8, no. 7, pp. 1273-1283, 2015.

[2] Sheng $\mathrm{Xu}, \mathrm{Wu} \mathrm{Ca}$, Shunyu Wang, and Jianfeng Zhao, "Analysis and Control of Switching Circulating Currents in Multi-Module Parallel SPWM Converters,” IEEE Access, vol. 6, pp. 32637-32648, 2018.

[3] P. Monica, and M. Kowsalya, "Control strategies of parallel operated inverters in renewable energy Application: A review," Renewable and sustainable energy reviews, vol. 65, pp. 885-901, 2016.

[4] Gabriel J. Capella, et al., "Current Balancing Technique for Interleaved Voltage Source Inverters with Magnetically-Coupled Legs Connected in Parallel," IEEE Transactions On industrial Electronics, vol. 62, no. 3, pp. 1335-1344, 2015.

[5] Abdelmalik Zorig, et al., "Sliding Mode Control and Modified SVM for Suppressing Circulating Currents in Parallel-Connected Inverters," Electric Power Components and Systems, vol. 46, no. 9, pp. 1061-1071, 2018.

[6] Chunwei Song, et al., "Circulating Current Elimination Scheme for Parallel Operation of Common DC Bus Inverters," International Journal of Electrical Power \& Energy Systems, vol. 63, pp. 17-29, 2014.

[7] Hao Ma1, Zhao Lin1 , Liang Dong, Qian Guo, "Modeling and analysis of switching frequency circulating current in three-phase parallel inverters," 2014 IEEE 23rd International Symposium on Industrial Electronics (ISIE), Istanbul, 2014, pp. 568-573.

[8] Tongsheng Zhang, et al., "Zero-sequence circulating current control method for parallel three-level T-type inverters using SHEPWM," 2016 IEEE 8th International Power Electronics and Motion Control Conference (IPEMC-ECCE Asia), Hefei, 2016, pp. 2382-2388.

[9] Anatolii Tcai, Sante Pugliese and Marco Liserre, "Discontinuous modulation of interleaved parallel NPC inverters with reduced circulating current," 2019 IEEE Energy Conversion Congress and Exposition (ECCE), Baltimore, MD, USA, 2019, pp. 4403-4408.

[10] Dongsul Shin, "Stability Improvement of Interleaved Voltage Source Inverters Employing Coupled Inductors for GridConnected Applications," IEEE Transaction on Power Electron Industrial Electronics, vol. 62, no. 10, pp. 6014-6023, 2015.

[11] Zhang Xueguang, et al., "Dead-beat Control Strategy of Circulating Currents in Parallel Connection System of Three-Phase PWM Converter," IEEE Transactions on Energy Conversion, vol. 29, no. 2, pp. 406-417, 2014.

[12] Heng Wu, and Xiongfei Wang, "Dynamic impact of ZSCC on modular multilevel converters: complex-valued AC impedance modeling and analysis," IEEE Journal of Emerging and Selected Topics in Power Electronics, vol. 8, no. 2, pp. 1947-1963, 2020.

[13] Ahmed Majeda, Zainal Salama, Abdul Moeed Amjad, "HEPWM based direct control for 23-level Multilevel Distribution statcom," Electric power systems research, vol. 152, pp. 48-60, 2017.

[14] Georgios Konstantinou, et al., "Reducing circulating currents in interleaved converter legs under selective harmonic elimination pulse-width modulation," 2015 IEEE International Conference on Industrial Technology (ICIT), Seville, 2015, pp. 1136-1141.

[15] Karthikeyan Venkitusamy, et al., "A modified boost rectifier for elimination of circulating current in power factor correction applications," Microelectronics Reliability, vol. 69, pp. 29-35, 2017.

[16] Federico M. Serra, and Cristian H. De Angelo, "IDA-PBC controller design for Grid connected Front End Converters under non-ideal Grid conditions," Electric Power Systems Research, vol. 142, pp. 12-19, 2016.

[17] Wei He, Carlos Abraham Soriano-Rangel, Romeo Ortega, Alessandro Astolfi, "Energy Shaping Control for BuckBoost Converters with Unknown Constant Power Load," Control Engineering Practice, vol. 74, pp. 33-43, 2018.

[18] Shi, Ying Xu, Meng Liao, Shuqiang Guo, Yuanyuan Li, Li Ren, Rongyu Su, "Integrated design method for superconducting magnetic energy storage," Applied Energy, vol. 248, pp. 1-17, 2019.

[19] Suroso, Daru Tri Nugroho, Toshihiko Noguchi, "New dead-time compensation method of power inverter using carrier based sinusoidal plse width modulation," International Journal of Electrical and Computer Engineering (IJECE), vol. 8, no. 6, pp. 4880-4891, 2018.

[20] Ghanshyamsinh Gohil, Ramkrishan Maheshwari, Lorand Bede, et al., "Modified Discontinuous PWM for Size Reduction of the Circulating Current Filter in Parallel Interleaved Converters," IEEE transaction on power electronics, vol. 30, no. 7, pp. 3457-3470, 2015.

[21] P. Monica, M. Kowsalya, P. C. Tejaswi, "Load sharing control of parallel opearted single phase inerters," Energy procedia, vol. 117, pp. 600-606, 2017.

[22] P. Suresh Babu, C. Ganesh and P. Venkta Subbaia, "Improved Droop Control Strategy for Grid-Connected Inverters," Indian journal of science and technology, vol. 8, no. 18, pp. 1-7, 2015.

[23] S. K. Khadem, M. Basu, M. F. Conlon, "Parallel opearion of inverters and active power filters in distributed generation system-A review," Renewable and sustainable energy reviews, vol. 15, no. 9, pp. 5155-5168, 2011.

[24] Alaa Mohd, Egon Ortjohann, Danny Morton, Osman Omari, "Review of control techniques for inverters parallel opeartion," Electric power systems research, vol. 80, no. 12, 1477-1487, 2010.

[25] Xiangjun Quan, Zaijun Wu, Xiaobo Dou, Minqiang Hu, Alex Q. Huang, "Load Current Decoupling Based LQ Control for Three-Phase Inverter," IEEE Transactions on Power Electronics, vol. 33, no. 6, pp. 5476-5491, 2018.

[26] Shengzhao Pang, et al., "Interconnection and Damping Assignment Passivity-Based Control Applied to On-Board DC-DC Power Converter System Supplying Constant Power Load," IEEE Transactions on Industry Applications, vol. 55, no. 6, pp. 6476-6485, 2019. 


\section{BIOGRAPHIES OF AUTHORS}
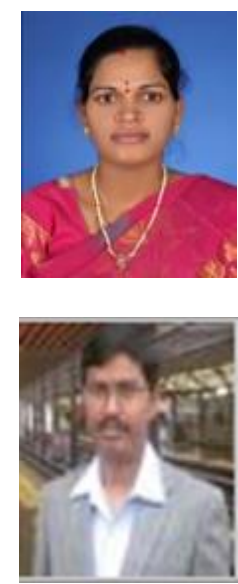

Sravanthy Gaddameedhi is presently working as an Assistant Professor in department of Electrical and Electronics Engineering at Sreenidhi Institute of Science and technology, Hyderabad, Telangana, India. She received her B.Tech in Electrical and Electronics Engineering in 2008 from JNTU Hyderabad and M.Tech in Power Electronics in 2010 from JNTU Hyderabd, Telangana, India. Currently, she is pursuing Ph.D in deprtment of Electrical Engineering at Osmania University, Hyderabad,Telangana India. Her special field of interest includes Power Electronics, Electrical Drives \& Control and FACTS. E-mail ID: sravanthig @ sreenidhi.edu.in

P. Srinivas is presently working as a Professor in Department of Electrical Engineering,University College of Engineering, Osmania Univesity, Hyderabad, Telangana, India. He received his B.Tech in Electrical and Electronics Engineering in 1998 from Kakatiya University (KU), Warangal and M.tech in Electrical machines and Industrial drives in 2000 from NIT Warangal, and Ph.D degree in switched reluctance motor in 2013 from Osmania University, Hyderabad,Telangana, India. His special field of interest includes Special Electrical Machines with Emphasis on switched Reluctance Machines, Electrical Drives and Control, Power Electronics Applications, and Artificial Intelligent Control of Electric Drives. Email ID: srinivasp.eedou@ rediffmail.com 